\title{
Optimizing subsurface dripline installation depth with Hydrus 2D/3D to improve irrigation water use efficiency in the central Tunisia
}

Hiba Ghazouani ${ }^{1,2}$, Boutheina Douh M'hamdi ${ }^{1, \star}$, Dario Autovino ${ }^{2}$, Amel Mguidiche Bel Haj ${ }^{1}$, Giovanni Rallo ${ }^{2}$, Giuseppe Provenzano ${ }^{2}$, and Abdelhamid Boujelben ${ }^{1}$

1 Department of Rural Engineering, Higher Institute of Agronomy of Chott Mariem(ISA-CM), BP 47, 4042 Sousse, Tunisia

2 Department of Agricultural and Forest Sciences (DSAF), Università degli Studi di Palermo, Viale delle Scienze 12, 90128 Palermo, Italy

Received: 7 July 2015 / Accepted: 17 October 2015

\begin{abstract}
The main objective of the work is to optimize drip installation depth for Eggplant crop irrigated with surface or subsurface drip irrigation systems to improve irrigation Water Use Effeciency (WUE), by means of field measurements and simulations carried out with Hydrus-2D model. Initially, a comparison between simulated Soil Water Contents (SWC) and the corresponding measured in two plots, in which laterals with coextruded emitters are laid on the soil surface (T0) and at $20 \mathrm{~cm}$ depth (T20), respectively. In order to choose the best position of the lateral, the results of different simulation run, carried out by choosing a deeper installation (T45) depth. Simulated SWC's resulted fairly close to the corresponding measured at different distances from the emitter and therefore the model was able to predict SWC's in the root zone with values of the Root Mean Square Error generally lower than $4 \%$. This result is consequent to the appropriate schematization of the root distribution, as well as of the root water uptake. The values of WUE associated to the different examined installation depths tend to a very slight increase when the position of the lateral is situated on $20 \mathrm{~cm}$ and start to decrease for the higher depths.
\end{abstract}

Keywords: Subsurface drip irrigation, soil water contents, Hydrus 2D, water use efficiency, RMSE

\section{Introduction}

With the raise of population in the last decades, food and water demand have been increased. The expansion of cultivated areas was therefore necessary in order to improve food and water security. Forecasts for the future predict a greater competition to reallocate water for industrial and urban needs. However, irrigated agriculture uses more and more water in a global scale, reaching a consumption of $70-80 \%$ of the total water resources, especially in arid and semi arid regions. In those areas, irrigation is considered as a key factor to intensify agricultural productivity and to fulfil sustainable agricultural development.

In the semi arid environment of Tunisia, National water policies aim to increase irrigated areas and mobilize surface and groundwater. In fact, irrigated areas rose from 65000 ha in 1956 to 408000 ha in 2010. Actually, with a percentage of $8 \%$ of the potential cultivable lands, irrigated areas provide $35 \%$ of the total agricultural production [1]. According to General Direction of water resources (2004), the country receives in average $230 \mathrm{~mm}$ for a year. Conventional water resources reach $4840 \mathrm{Mm}^{3} \mathrm{y}^{-1}$ divided in $2700 \mathrm{Mm}^{3}$ of surface water, concentrated mainly in the north, and $1969 \mathrm{Mm}^{3} \mathrm{y}^{-1}$

* Correspondence: boutheina_douh@yahoo.fr of ground water $50 \%$ of conventional water is showing a salinity exceeding $1.5 \mathrm{~g} \mathrm{l}^{-1}$ and $47 \%$ Of groundwater have a salinity higher than $3.5 \mathrm{~g} \mathrm{l}^{-1}$. To overpass the problem of water scarcity, Tunisian strategy for water management made it possible to use water with low quality. Nevertheless, a reasonable and sustainable water use is being more and more compulsory and cannot be deferred. Subsurface drip irrigation, providing small quantity of water under high frequency keeping in that way the root zone under high water content and nutriment concentration, are increasingly considered as a powerful strategy to optimize irrigation efficiency.

For those systems, the distribution of soil wetted areas is quietly affected by the soil proprieties and the considered flow rate [2-4], depth and spacing of the line and emitter spacing and flow rate $[3,5,6]$ and irrigation scheduling and management including irrigation frequency and the amount [2,7-9]. In addition, dripline depth have to be chosen based on the crop, soil and climate conditions, the know-how of the farmers and the water quality [3]. If from one side, several studies investigated on the effect of the dripline on germination [10,11], crop yield and fertilizer saving, a few past studies have been carried out to optimize WUE of high value crop like eggplant, especially under the central Tunisia. 
For area with limited water resources, agro hydrological models can be considered as an important tool to predict soil water dynamic and to provide guidelines for plant design and for optimizing irrigation water use [12]. Hydrus $2 \mathrm{D} / 3 \mathrm{D}$ is numerical software that simulates water and solute movement in porous media [13]. A number of past studies confirmed the suitability of Hydrus 2D for simulating water infiltration and solute transport for a buried emitter $[6,14]$. Moreover, after site validation, the model could be used to define the optimum installation depth to improve water use efficiency, after a number of simulations identifying the evolution of water content, soil potential and actual/potential transpiration.

With these background considerations, a comprehensive field and simulation investigations have been carried out under the central Tunisia climate. The main objective of the work is to evaluate, in a sandy loam soil the optimal dripline depth for Eggplant crop (Solanum melongena L.). Initially, a comparison between the punctual simulated soil water contents with the corresponding measured in the field for drip laterals, placed at two different positions (on the soil surface (T0), and at $20 \mathrm{~cm}$ depth (T20)), were considered in order to evaluate the performance of the model to well simulate water content in the root zone. Then, a different simulation run were carried out by changing the installation depth at $45 \mathrm{~cm}$ (T45) in order to choose the best position of the lateral. The results of simulations were finally compared in terms of ratio between actual transpiration and total amount of water, provided during the entire growing season, in other words in terms of water use efficiency.

\subsection{Numerical water distribution modelling}

Hydrus-2D is software who simulates soil water content in a variably saturated medium and for a vertical flux (drip line). The government numerical model used by hydrus$2 \mathrm{D}$ is the two dimensional Richard's equation which is expressed in a case of an homogeneous and isotropic soil as bellow:

$$
\frac{\partial \theta}{\partial t}=\frac{\partial}{\partial x}\left[K(h) \frac{\partial h}{\partial x}\right]+\frac{\partial}{\partial z}\left[K(h) \frac{\partial h}{\partial z}+K(h)\right]-S(x, z, t),
$$

where $\theta\left[\mathrm{L}^{3} \mathrm{~L}^{-3}\right]$ is the volumetric soil water content, $t[\mathrm{~T}]$ is the time, $x[\mathrm{~L}]$ and $z[\mathrm{~L}]$ are the horizontal and vertical space coordinates, $h[\mathrm{~L}]$ is the soil water $p$ head, $K\left[\mathrm{~L} \mathrm{~T}^{-1}\right]$ is the unsaturated hydraulic conductivity and finally, $S(r$, $z, t)\left[\mathrm{L} \mathrm{T}^{-1}\right]$ is a sink term expressing the rate of root water uptake [15].

Using Galerkin finite elements method and based on an iterative mass conservation, Hydrus 2D/3D was used to resolve equation (1).

Soil hydraulic parameters have been modelled by Genuchten-Mualem (van Genuchten (1980), Mualem (1976)) [15] using the water retention curve and the satu- rated soil hydraulic conductivity.

$$
\begin{aligned}
\theta & =\theta_{r}+\left(\theta_{s}-\theta_{r}\right) \frac{1}{\left[1+|\alpha h|^{n}\right]^{m}} \\
K(\theta) & =K_{s}\left[\frac{\left(\theta-\theta_{r}\right)}{\left(\theta_{s}-\theta_{r}\right)}\right]^{\lambda}\left[1-\left(1-\left(\frac{\left(\theta-\theta_{r}\right)}{\left(\theta_{s}-\theta_{r}\right)}\right)^{\frac{1}{m}}\right)^{m}\right]^{2}
\end{aligned}
$$

where $\theta_{r}$ and $\theta_{s}\left[\mathrm{~L}^{3} \mathrm{~L}^{-3}\right]$ are the residual and saturated soil water content, $K_{s}\left[\mathrm{~L} \mathrm{~T}^{-1}\right]$ is the saturated hydraulic conductivity, $\alpha\left[\mathrm{L}^{-1}\right]$ is a scaling factor, $n[-], m[-]$ and $\lambda[-]$ are empirical parameters.

The root water uptake pattern could be an additive or a multiplicative model. In that study, we did use the multiplicative model of Feddes [16] which is shown in the equation (4). This model allows define the water uptake rate in any generic point of the root zone according to its pressure head. It determine by this way the reduction in the transpiration rate when the soil can no longer provide for the plant the required amount to reach potential transpiration.

$$
S(h)=\gamma(h) S_{p},
$$

where $S_{p}\left[\mathrm{~L} \mathrm{~T}^{-1}\right]$ is the potential water uptake $\left(S_{p}\right)$ and $\gamma(h)$ is a dimensionless water response function for water uptake. Feddes et al. (1978) proposed a linear model for water stress response function $\gamma(h)$ which involves five threshold variables: pressure head below which root water uptake occurs, $P_{0}$, pressure head below which rate for root extraction is maximum $P_{\mathrm{opt}}$, thresholds of pressure head below which the rate of roots extraction is lower than the maximum $P_{2 \mathrm{H}}$ and $P_{2 \mathrm{~L}}$, evaluated according to the high $\left(r_{2 \mathrm{H}}\right)$ or low $\left(r_{2 \mathrm{~L}}\right)$ potential transpiration rates and finally, pressure head below which root water uptake ceases, $P_{3}$.

The maximum potential transpiration rate $(T p)$ must be calculated related to the spatial root distribution which influence in a big range soil water content, drainage and water uptake. The two dimensional model for root distribution used by Hydrus 2-D was expressed by Vrugt et al. (2001) by the following equation:

$$
\begin{aligned}
\beta(r, z)= & \left(1-\frac{z}{z_{\max }}\right)\left(1-\frac{r}{r_{\max }}\right) \\
& \times \exp \left(-\left(\frac{p_{z}}{z_{\max }}\left|Z^{*}-z\right|+\frac{p_{r}}{r_{\max }}\left|R^{*}-r\right|\right)\right),
\end{aligned}
$$

where $r_{\max }$ and $z_{\max }$ are the maximum radial and vertical distance beyond which root density is zero; $p_{z}, p_{r}, R^{*}$, and $Z^{*}$ are empirical parameters that can obtained with experimental observations. These parameters can account for asymmetrical root water uptake with depth and radius and allow evaluation of the maximum root water uptake at any depth [17].

\subsection{Model processing, geometry system and input parameters}

Hydrus-2D have been used to reproduce a natural processes related to water flow and root uptake. Objectives 
of the elaborated simulations were to analyse the water distribution under different installation depth in order to increase water use efficiency in the semi arid environment. For the both dripline positions, a simulation domain of $80 \mathrm{~cm}$ depth and $60 \mathrm{~cm}$ width was considered. As it was an axisymetric plan and the same phenomena was reproduced along the drip line, only a single emitter was been reproduced.

For the traditional DI, a constant flux density of $5.0 \mathrm{~cm} \mathrm{~h}^{-1}$, obtained dividing the emitter flow discharge by a rectangular wetted area of $20 \mathrm{~cm}$ wide and $40 \mathrm{~cm}$ length was considered. On the other hands, the buried water source (SDI) was schematized as a cylinder $1.0 \mathrm{~cm}$ radius and $20 \mathrm{~cm}$ length so that flux density, according to the emitter flow rate, resulted equal to $15.9 \mathrm{~cm} \mathrm{~h}^{-1}$.

Simulation domain was discretized with 1378 nodes corresponding to 2635 triangular elements for DI and with 1237 nodes, corresponding to 2353 triangular elements for SDI. For both the treatments, the flux density corresponding to the emitter discharge was assumed at the emitter boundary surface during irrigation, whereas the absence of flux was considered in the following redistribution processes. Atmospheric boundary conditions were considered in the soil surface of the reproduced domain. Due to the summitry of the profile, left and right boundary conditions were assumed equal to zero. The computation flow domain was made with a free drainage bottom condition. This assumption was crucial according to the climatic condition of the experimental year and the variability of soil water content at $75 \mathrm{~cm}$.

Simulations were run from April 1, during the initial phase of crop development to the end of June, a few days before harvesting. The amount of water supplied during the simulation period is the same for both the treatments (DI and SDI), divided in 10 watering providing in total $83.3 \mathrm{~mm}$ of water. In order to take into account the evolution of the root system during the growing period, a total of 3 simulations were run. Initial soil water content within the soil profile was assumed linearly variable between $0.18 \mathrm{~cm}^{3} \mathrm{~cm}^{-3}$ and $0.22 \mathrm{~cm}^{3} \mathrm{~cm}^{-3}$, according to the average values measured at the different depths on April 1, in both the sub-plots, immediately before irrigation. In the other simulations, initial soil water contents in the simulation nodes were assumed equal to the corresponding final values of the previous simulation. Soil hydraulic functions (water retention curve and conductivity function), root water uptake and root distribution models, crop response function to water stress and their related parameters, as used in simulations, are indicated in Table 1.

\section{Materials and methods}

\subsection{Site descriptions and experimental layout}

The research was carried out, from April to June 2007, at the experimental site of "Higher Agronomic Institute of Chott Meriem in Sousse, Tunisia (Longitude $10.5604^{\circ} \mathrm{E}$, Latitude $35.9130^{\circ} \mathrm{N}$, Altitude $15 \mathrm{~m}$ a.s.l.). The experimental plot was divided in two $25 \mathrm{~m}$ large and $40 \mathrm{~m}$ long sub-
Table 1. Parameterization of Soil hydraulic, root water uptake and root distribution models in Hydrus-2D simulations.

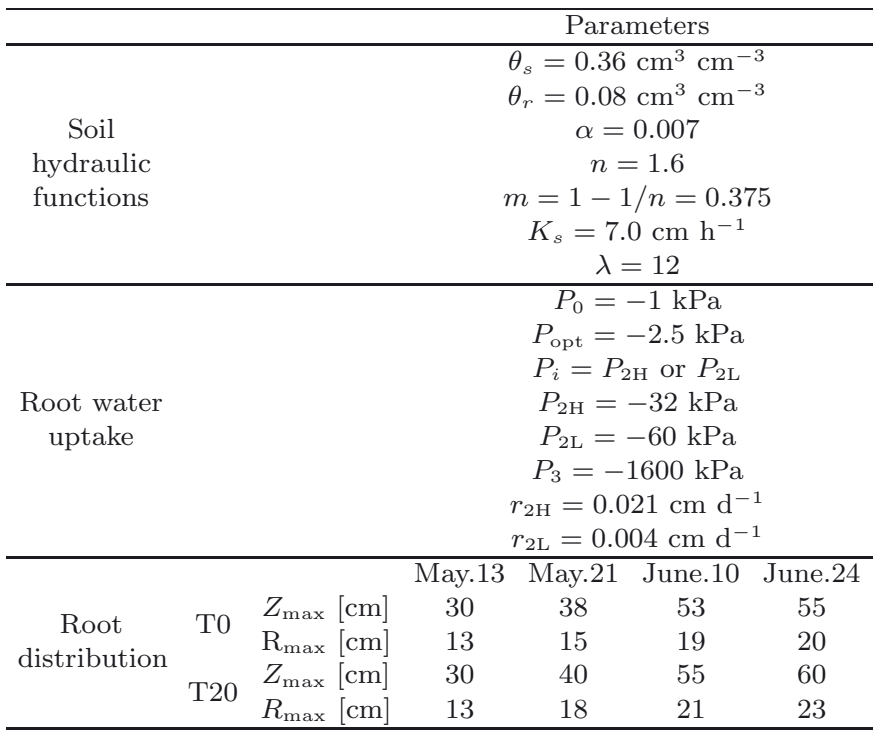

$\theta_{s}$ : Saturated water content; $\theta_{r}$ : Residual water content; $\alpha$ : Inverse of the air-entry value; n: pore size distribution index; $K_{s}$ : Saturated hydraulic conductivity; $\lambda$ : pore-connectivity parameter; $S(P)$ Root water extraction as a function of soil matric potential $P$; $S_{\max }$ : Maximum water extraction by roots $P_{0}$ : Pressure below which roots extract water from the soil; $P_{\mathrm{opt}}$ : Pressure below which roots extract water at a maximum rate; $P_{2 \mathrm{H}}$ : Limiting pressure below which roots no longer extract water at a maximum rate under potential transpiration rate of $r_{2 \mathrm{H}} ; P_{2 \mathrm{~L}}$ : Pressure below which roots no longer extract water at a maximum rate under potential transpiration rate of $r_{2 \mathrm{~L}}$, $P_{3}$ : Pressure head below which root water uptake ceases; $r_{2 \mathrm{H}}$ : Potential transpiration rate at high atmospheric demand; $r_{2 \mathrm{~L}}$ : Potential transpiration rate at low atmospheric demand; $Z_{\max }$ : Maximum rooting depth; $R_{\max }$ : Maximum rooting length in the radial direction; $r$ : Radial distance.

plots in which eggplants (Solanum melongena L.) were planted with spacing between the rows of $1.2 \mathrm{~m}$ and along the rows of $0.40 \mathrm{~m}$. The first sub-plot was irrigated by means of traditional drip irrigation (T0) with laterals laid on the soil surface, whereas the second was irrigated with a subsurface drip irrigation (T20) system, with laterals installed at $0.20 \mathrm{~m}$ below the soil surface. Emitters in coextruded laterals were spaced $40 \mathrm{~cm}$ and characterized by a flow rate of $2.0 \mathrm{l} \mathrm{h}^{-1}$ at a nominal pressure of $100 \mathrm{kPa}$.

In order to estimate reference evapotranspiration, $E T_{0}$, meteorological standard variables (air temperature, humidity, global radiation, precipitation and wind speed at $2 \mathrm{~m}$ ) were acquired from a weather station installed about $300 \mathrm{~m}$ far from the experimental site. Daily values of $E T_{0}$ were determined according to modified FAO Penman-Monteith equation [18]. FAO "dual crop coefficient approach" was then used for partitioning $E T_{0}$ in potential soil evaporation, $E_{p}$, and crop transpiration, $T_{p}$. according to the basal crop coefficient, $K_{c b}$ and the evaporation coefficient $K_{e}$, respectively.

Spatial and temporal variability of soil water contents was acquired with a Time Domain Reflectometry (TDR) 


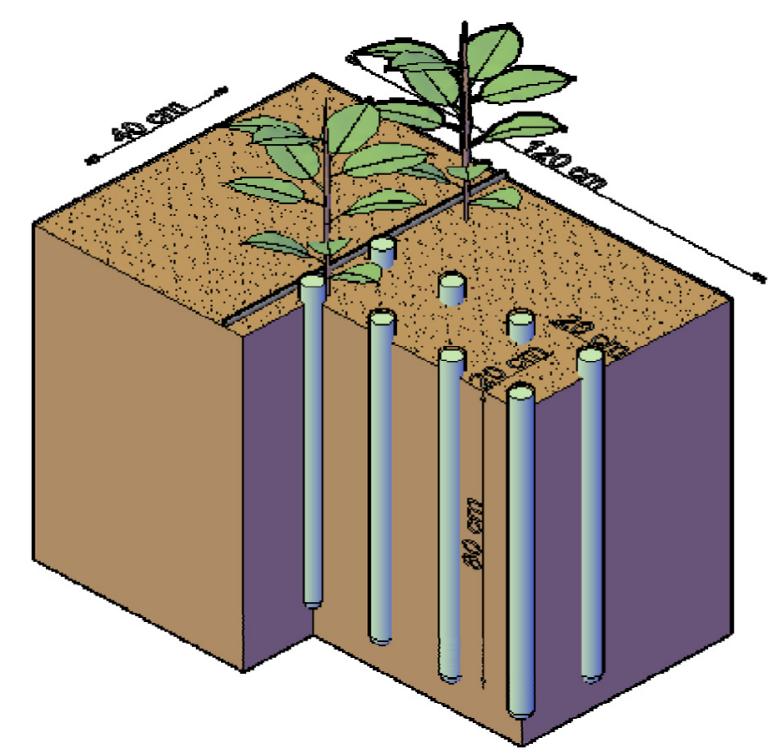

Fig. 1. Position of access tubes for the TDR sensor installed in both the sub-plots.

probe, (Trime-FM3, IMKO Micromodultechnik GmbH, Germany). The sensor, inserted in plastic access tubes preventively installed in the soil, allowed to measure volumetric water contents of a soil volume with diameter and height equal to about $15 \mathrm{~cm}$.

A total of four access tubes $70 \mathrm{~cm}$ long were installed in each sub-plot, along the direction perpendicular to the plant row at distances of $0 \mathrm{~cm}, 20 \mathrm{~cm}, 40 \mathrm{~cm}$ and $60 \mathrm{~cm}$ from the emitter, as showed in Figure 1; soil water contents were regularly measured during the investigation period at depths of $15 \mathrm{~cm}, 30 \mathrm{~cm}$ and $45 \mathrm{~cm}$.

Irrigation water was supplied, taking into account the rainfall events, every $7-10$ days at the beginning of the crop cycle (March and April) and approximately once a week during the crop full development stage and harvesting (May and June), for a total of 15 watering of $1 \mathrm{~h}$.

\section{Results and discussion}

\subsection{Agro-meteorological characterization}

The dynamic of agro-meteorological variables (global solar radiation, air temperature and relative humidity, wind speed at $2 \mathrm{~m}$ above the ground, as well as rainfall and reference evapotranspiration), measured during the growing season 2007, is shown in Figures 2a-2d. For the considered period, daily values of $E T_{0}$ increased, according to the climatic conditions, from $2.0 \mathrm{~mm} \mathrm{~d}^{-1}$ at the end of February to about $4.0 \mathrm{~mm} \mathrm{~d}^{-1}$, at the end of June. Precipitations events occurred till the end of April, with the exception of two insignificant events in May. Due to the reduced irrigation volumes and the high environmental request, during the simulation period the crop was subjected to severe water stress conditions.

Figure 3a shows the distribution of precipitation and irrigation during the growing season. Irrigation scheduling followed the ordinary management practiced in the surrounding area, with a total depth, provided from February 17, equal to about $115 \mathrm{~mm}$ divided in 15 watering. During the growing season the total precipitation height resulted equal to $120 \mathrm{~mm}$.

Figure $3 \mathrm{~b}$ illustrates the daily values of potential crop transpiration, $T_{p}$, and soil evaporation, $E_{p}$, being the former estimated on the basis of $E T_{0}$ and assuming the values of crop coefficient, $K_{c b}$, and the duration of phonological stages as suggested by [18] and showed in Figure 3b. As can be observed, $T_{p}$ tends to increase during the growing season, from mid of March to the end of June, rising from $0.4 \mathrm{~mm} \mathrm{~d}^{-1}$ to about $4.0 \mathrm{~mm} \mathrm{~d}^{-1}$, according to of $E T_{0}$ and $K_{c b}$. During the full development stage, daily values of $T_{p}$ resulted variable between 3 and $4 \mathrm{~mm} \mathrm{~d}^{-1}$, according to the variability of $E T_{0}$. On the other hands, potential soil evaporation $E_{p}$, initially ranging between 0.5 and $1.0 \mathrm{~mm} \mathrm{~d}^{-1}$, decreased to very low values, equal on average to $0.1 \mathrm{~mm} \mathrm{~d}^{-1}$, after mid of April, in absence of significant rainfall events.

Figure 3c shows, for the considered period, the cumulative values of precipitation and irrigation, $\mathrm{P}+\mathrm{I}$, potential crop transpiration, $T_{p, c u m}$, and soil evaporation, $E_{p, c u m}$. As can be observed, cumulative transpiration during the growing season resulted $270 \mathrm{~mm}$, slightly higher than cumulative water supply, $\mathrm{P}+\mathrm{I}$, equal to $235 \mathrm{~mm}$. The low value of cumulative soil evaporation at the end of the considered period, equal to only $60 \mathrm{~mm}$, is consequent to the small amounts of rainfall, as well as to the system used for irrigation.

\subsection{Simulation results}

Figures 4 and 5 show a comparison between measured and simulated soil water contents, respectively for treatments T0 and T20. As can be observed, Hydrus-2d allows well simulating the dynamic of punctual SWCs around an emitter during irrigation season. Moreover, in terms of average values, it is possible to notice that simulated values are located in the range of variability of the corresponding measured. The values of Root Mean Square Error (RMSE), equal to $0.037 \%$ and $0.038 \%$ for treatments T0 and T20, resulted of the same order of magnitude of the error associated to the measurements $( \pm 0.03)$. This result evidenced that the model could be used as an accurate tool to simulate soil water contents, for the different lateral positions. However, it is also noticeable that the model presented a better performance for T20 than T0. This could be explained by a defective parameterization of the surface layer soil hydraulic functions, and to the possibility of the occurrence of air gaps, in the surface, between the access tube and the surrounding soil [19]. Based on the presented curves, we can deduce that the values of water content ranged between $22 \%$ and $25 \%$ maximum and were equal to $10 \%$ as a maximum. Qualitatively, the comparison between measured and simulated values of soil water content can be considered acceptable for the whole profile specially in averages, In fact the range of variation of the simulated values are situated within the range of variation of the measured ones. These results justify 

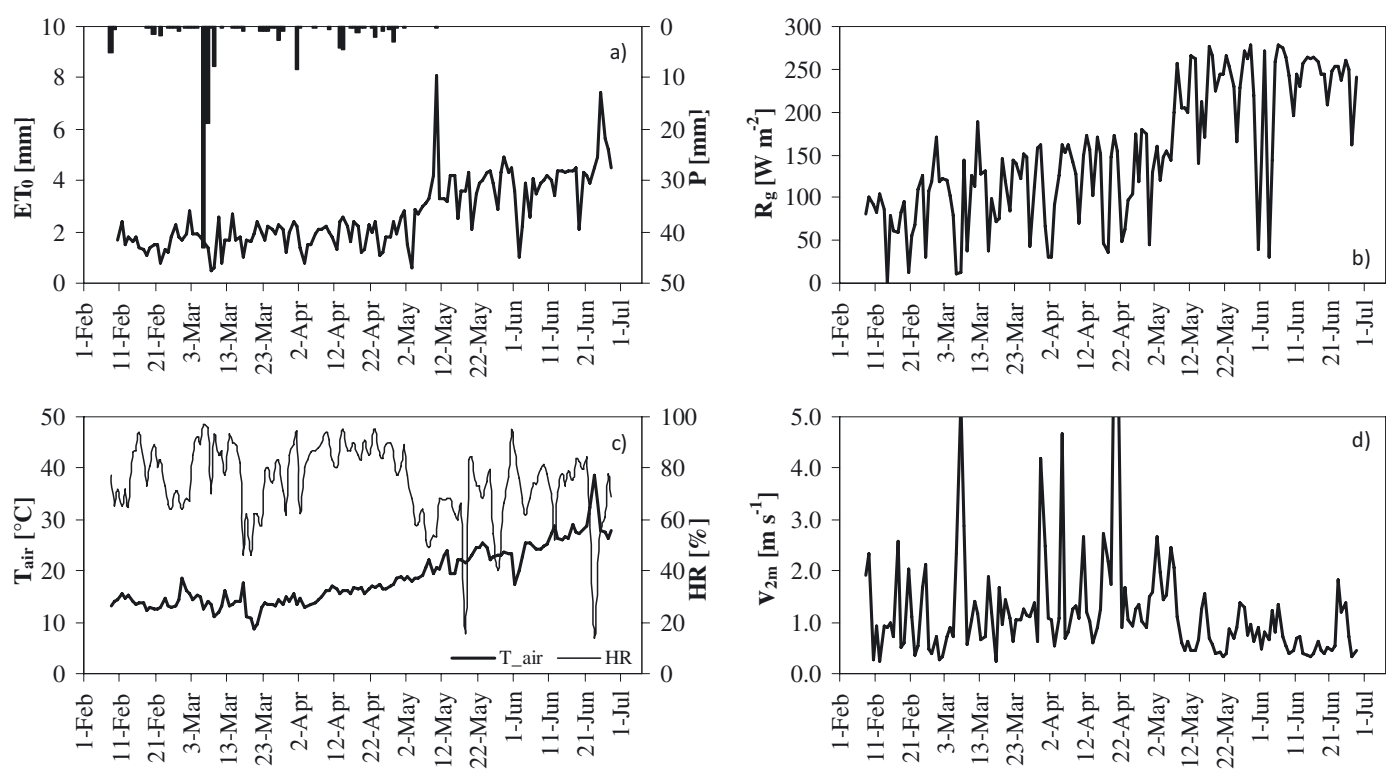

Fig. 2. (a) Daily values of a reference evapotranspiration, $E T_{0}$, and precipitation, $P$, measured during the growing season 2007), (b) global solar radiation, $R_{g}$, (c) air temperature, $T_{a i r}$, and relative humidity, $R H$, (d) wind speed at $2 \mathrm{~m}$ above the ground, $v_{2 m}$.

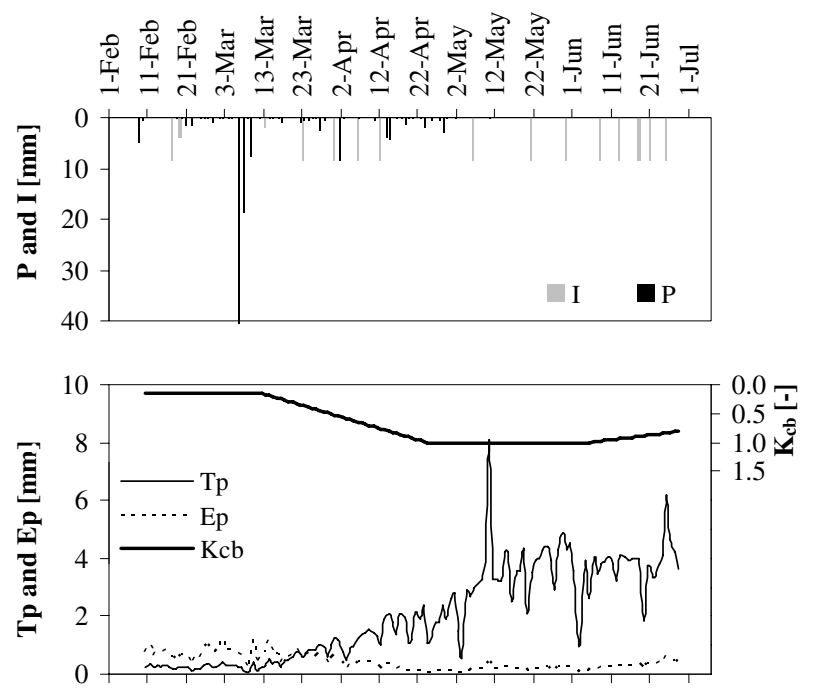

the use of Hydrus 2D/3D model as an accurate tool for evaluating actual and potential evapotranspiration and So on to judge water use efficiency.

\subsection{Optimizing the drip line to enhance water use efficiency}

In this section investigated on the optimal depth of irrigation lines. For that, a simulation run in which the emitters were buried at $45 \mathrm{~cm}$ was done. The results of that simulation was joined to the other two already developed simulations during the phase of model parameterization and where the drip line were installed at surface and at $20 \mathrm{~cm}$ of depth, respectively in T0 and T20 in order exanimate the optimal emitter depth position. The water content maps before and after the irrigation of 8 June, obtained for the whole simulations are presented in Figure 6 . It is noticeable from the analysis of these maps, that there was

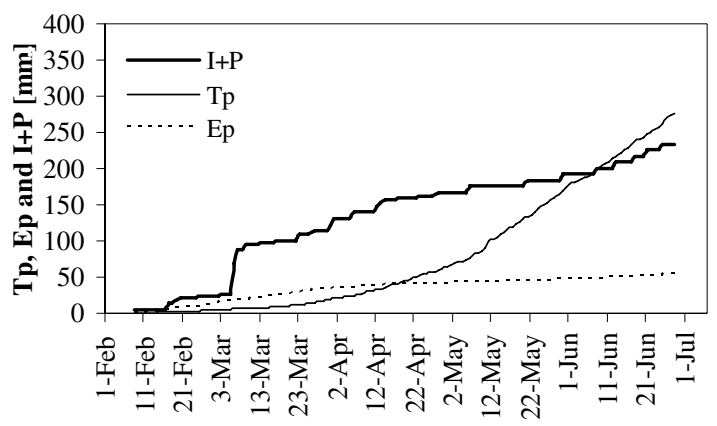

Fig. 3. (a) Irrigation and Precipitation distribution, (b) daily values of potential evaporation, $E_{p}$, and transpiration, $T_{p}$, during the growing period (basal crop coefficient, $K_{c b}$, is shown on the secondary axes) and (c) cumulative irrigation and precipitation, I+P, potential soil evaporation, $E_{p, c u m}$, and plant transpiration, $T_{p, c u m}$, during the growing period. a difference in the water content distribution between T0, T20 and T45. This difference varies depending on the time and depth of irrigation lines. For the scenarios (T0), the changes in water content are mainly related to the importance of the evaporation in that layer. Therefore, installing the drip line in the surface lead to important losses by evaporation. In treatment (T20), the water reaches deeper layers. The capillary rise processes will increase and modify the distribution of soil water stock. So the evaporation still present but it is indirectly established in this case. For a depth of $45 \mathrm{~cm}$ (T45), there is not evaporation however a great quantity of water is lost by deep drainage and water content on deeper levels become higher. Figure 7 shows the trend of the irrigation water use efficiencies. It is recognisable from the analysis of the figure that the drip line installation depth widely affects the water use efficiency. In particular, it is noticeable that the yield is lower for 


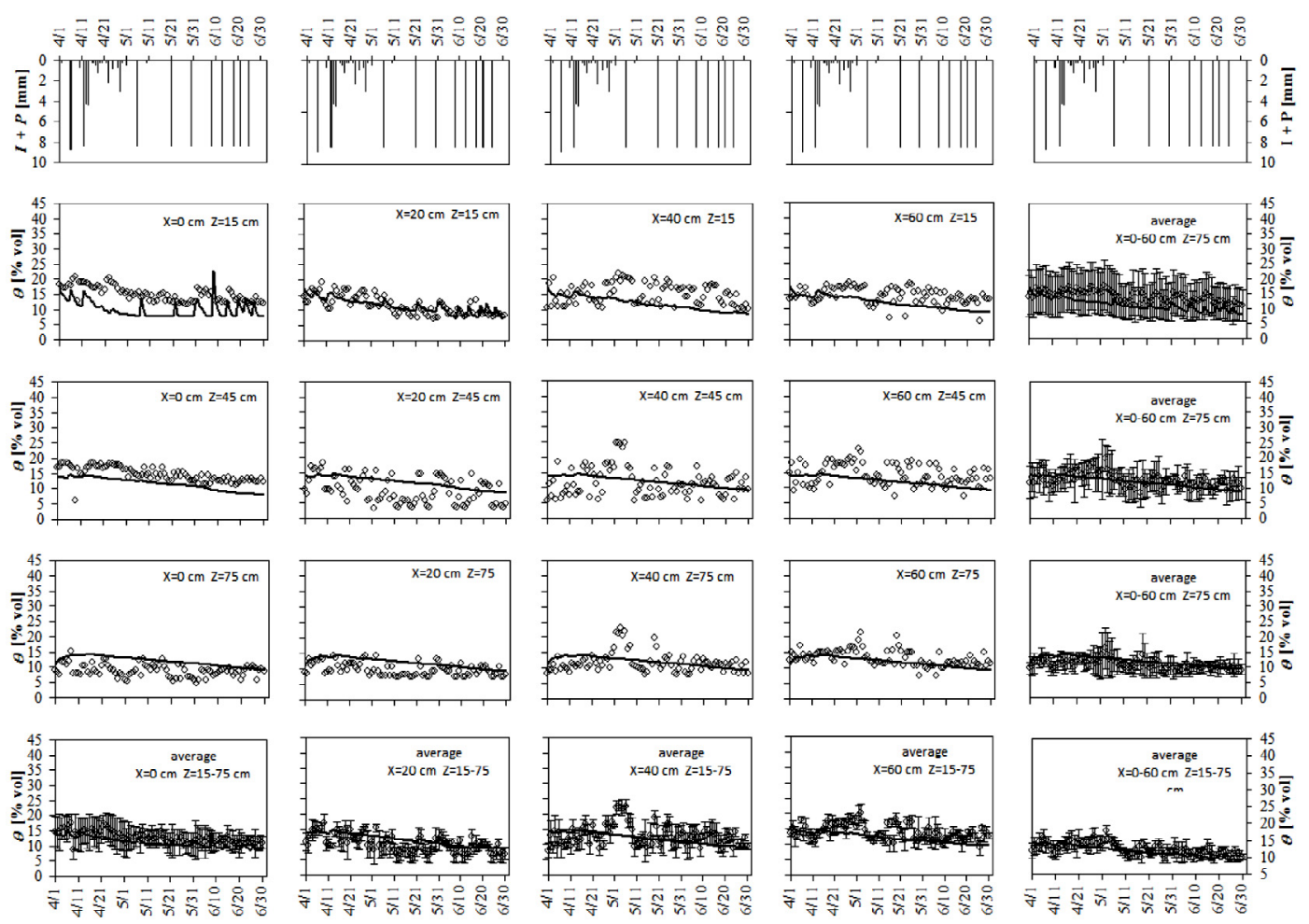

Fig. 4. Comparison between measured and simulated SWCs at distances of 0, 20, 40 and $60 \mathrm{~cm}$ from the emitter and depths of 15, 45 and $75 \mathrm{~cm}$, for T0 treatment. For each depth or distance from the emitter, the comparison between the average measured SWCs and their standard deviation with the corresponding simulated values is shown. Amount of rainfall and irrigation are also indicated in the upper row of the figure.
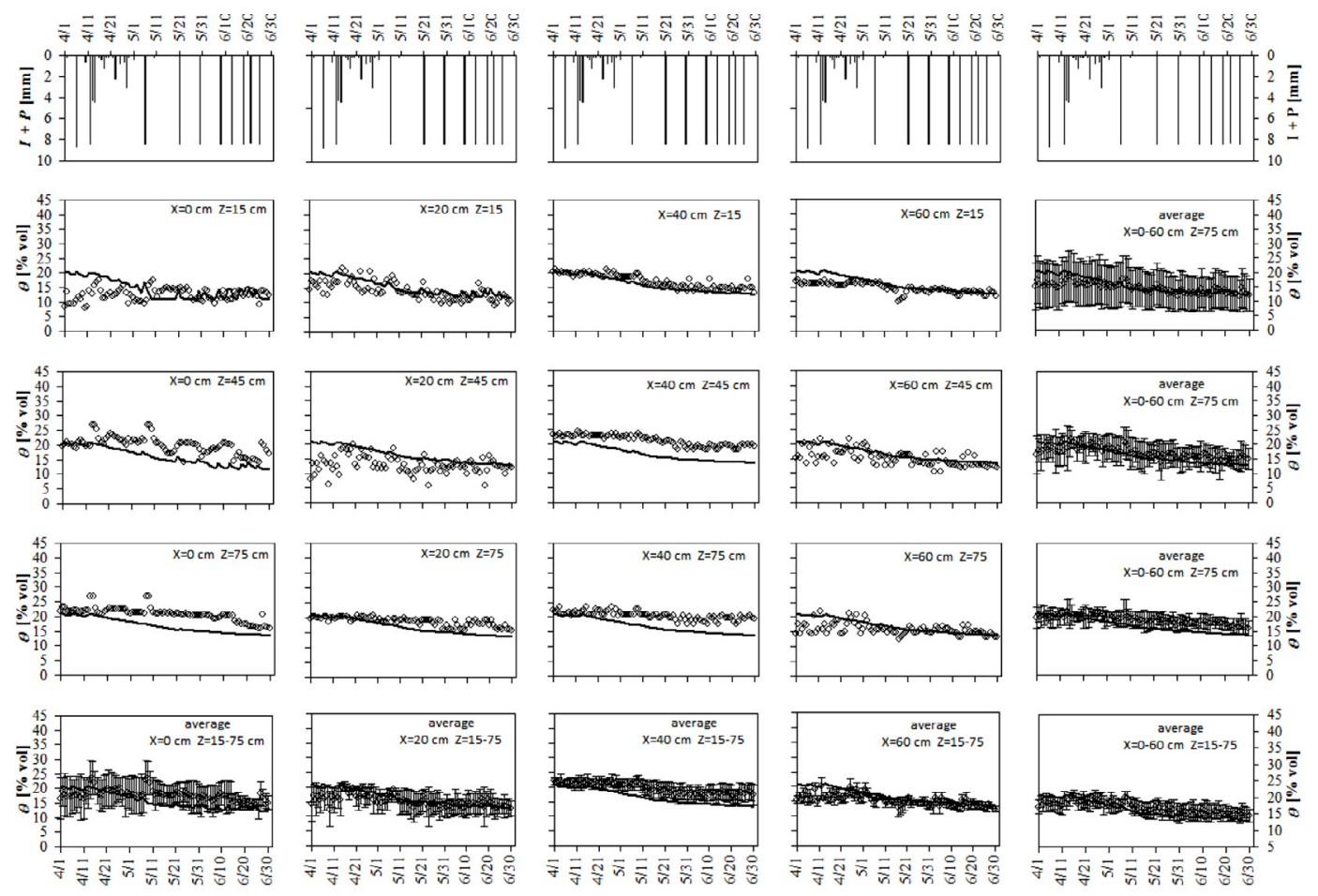

Fig. 5. Comparison between measured and simulated SWCs at distances of 0,20,40 and $60 \mathrm{~cm}$ from the emitter and depths of 15, 45 and $75 \mathrm{~cm}$, for T20 treatment. For each depth or distance from the emitter, the comparison between the average measured SWCs and their standard deviation with the corresponding simulated values is shown. Amount of rainfall and irrigation are also indicated in the upper row of the figure. 


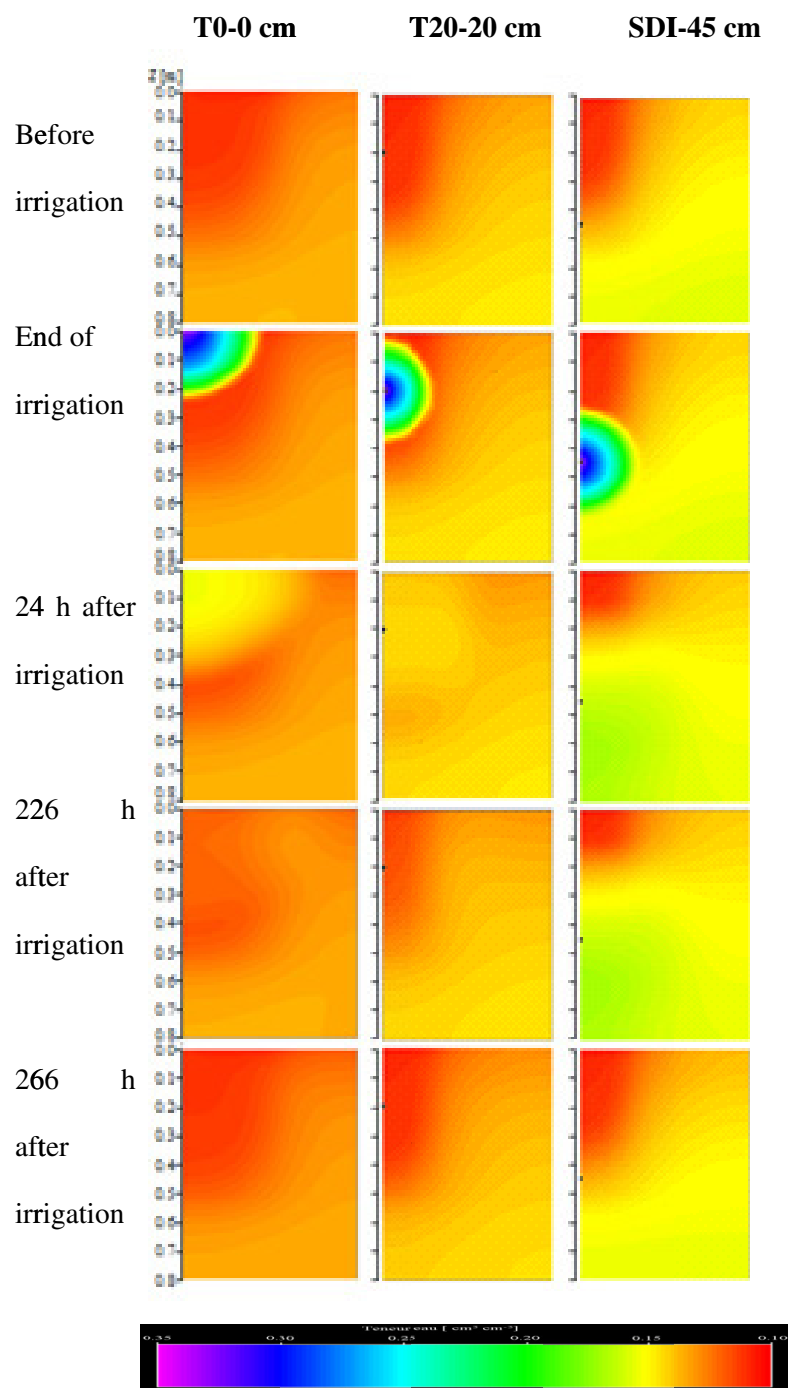

Fig. 6. Simulated distribution of soil water contents at different time-steps before and after irrigation provided on June 8, for emitter placed at different soil depth $(0,20$ and $45 \mathrm{~cm})$.

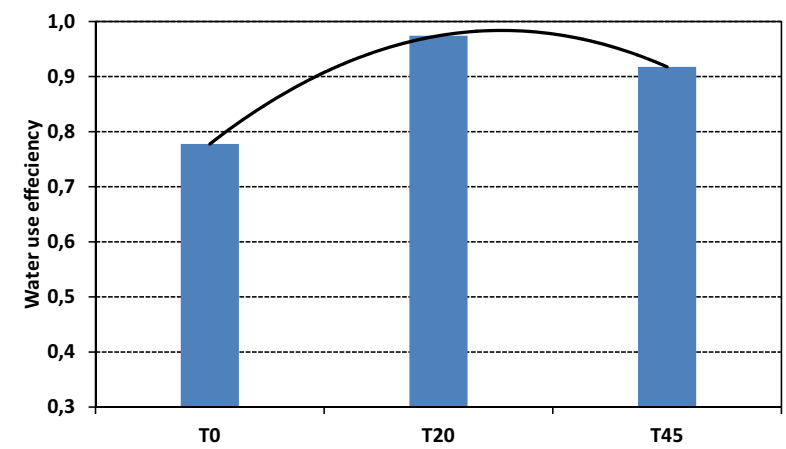

Fig. 7. Irrigation water use efficiency for emitter placed at different soil depth $(0,20$ and $45 \mathrm{~cm})$.

(T0) than the other treatment. This result could be explained by the importance of water loss by evaporation. However, for a depth of $45 \mathrm{~cm}$, the efficiency is lower compared with (T20), this could be attributed to the important loss by drainage, specially that the maximum rooting
Table 2. Terms of water balance for T0, T20 and T45.

\begin{tabular}{ccccc}
\hline $\begin{array}{c}\text { Termes of } \\
\text { water balance }\end{array}$ & & T0 & T20 & T45 \\
\hline Drainage & {$\left[\mathrm{m}^{3} \mathrm{ha}^{-1}\right]$} & 47.5 & 151.8 & 168.7 \\
Transpiration & {$\left[\mathrm{m}^{3} \mathrm{ha}^{-1}\right]$} & 1101.6 & 1380.0 & 1300.0 \\
Irrigation & {$\left[\mathrm{m}^{3} \mathrm{ha}^{-1}\right]$} & 833.3 & 833.3 & 833.3 \\
Rain & {$\left[\mathrm{m}^{3} \mathrm{ha}^{-1}\right]$} & 583.3 & 583.3 & 583.3 \\
IWUE & {$[-]$} & 0.78 & 0.97 & 0.92 \\
\hline
\end{tabular}

depth was about $55 \mathrm{~cm}$ for the surface irrigation and 60 , when the emitter were buried at $20 \mathrm{~cm}$. This processor can be observed in Table 2. Douh et al. [20] have tested pop corn crop on the same area of the semi arid climate of the Tunisian environment and found that Subsurface drip irrigation buried at $35 \mathrm{~cm}$ achieved a higher efficiency than the ones obtained with a subsurface drip irrigation system buried at 5 or $20 \mathrm{~cm}$. This finding was explained by the fact that a depth of $35 \mathrm{~cm}$ allows to uniform soil moisture, minimize the evaporative loss and delivery water directly to the plant root zone which increases use efficiency and yield. The difference between that result and the one obtained on the current study is justified by the difference of the rooting system development between both the trials.

Referring to the following table and Figure 7 we can conclude with a good approximation in terms of performance and efficiency of irrigation that the optimal depth of the installation is $20 \mathrm{~cm}$. In fact, and for the soil in question, the capillary rise process is low, so the indirectly loss by evaporative loss is low too.

\section{Conclusion}

Hydrus 2D model was tested for eggplants (Solanum melongena L.) under the semi arid environment of central Tunisia. The experiment was carried out the High Agronomic Institute of Chott Meriem. The field was divided in two $25 \mathrm{~m}$ large and $40 \mathrm{~m}$ long sub-plots in which eggplants (Solanum melongena L.) were planted with spacing between the rows of $1.2 \mathrm{~m}$ and along the rows of $0.40 \mathrm{~m}$. The first sub-plot was irrigated by means of with a drip irrigation system on which the laterals were laid to the surface (T0) whereas the second was irrigated with subsurface drip irrigation (T20) system, with laterals installed at $0.20 \mathrm{~m}$ below the soil surface. For each plot, spatial and temporal variability of SWCs were measured by mean of a Time Domain Reflectometry probe (Trime-FM3), on four $70 \mathrm{~cm}$ long access tubes, installed along the direction perpendicular to the plant row, at distances of 0, 20, 40 and $60 \mathrm{~cm}$ from the emitter. Irrigation water was supplied according to the how know of the farmers in the surrounding area, every $7-10$ days at the beginning of the crop cycle (March-April) and approximately once a week during the following stages till the harvesting (May-June), for a total of 15 one-hour watering.

Firstly, the ability of the model to well predict soil water content around a buried emitter was evaluated based on the root mean square error. The values of Root Mean 
Square Error (RMSE), equal to $0.037 \%$ and $0.038 \%$ for treatments T0 and T20, resulted of the same order of magnitude of the error associated to the measurements $( \pm 0.03)$. This last result justify the use of Hydrus 2D as an accurate tool to simulate as well as soil water content and potential and actual transpiration and to estimate therefore water use efficiency.

Analyzing the obtained maps of soil water content, it was recognized that a drip line laid to the soil surface leads to an important losses by evaporation, however when the laterals are installed in a depth of $20 \mathrm{~cm}$ the water reaches deeper layers, the capillary rises and contributes to indirectly evaporate some waer from the soil column. Moreover, a simulation run in which the drip lines are buried at $45 \mathrm{~cm}$ shows that the drainage is the main important phenomenon, which governs the water dynamics for that depth.

The experimental results, joined to model simulations provided useful guidelines for a more sustainable use of irrigation water in countries characterised by semi-arid environments and a limited availability of water resources.

Lower irrigation water use efficiency was obtained for (T0) than the other treatment. This result could be explained by the importance of water loss by evaporation. Morever, for a depth of $45 \mathrm{~cm}$, the efficiency is lower compared with (T20), which is contributed due to the important loss by drainage.

Referring to the experimental findings and the simulation results it could be concluded with a good approximation that in terms of performance and efficiency of irrigation, the optimal the installation depth is $20 \mathrm{~cm}$. In fact, and for the soil in question, the capillary rise process is low, so the indirectly loss by evaporative loss is low too. However, it will be also important to exanimate how the irrigation water use efficiency could vary if the emitter were buried under the soil surface and at a distance lower than $20 \mathrm{~cm}$.

\section{References}

1. B. Douh, A. Boujelben, Improving Water Use Efficiency for a Sustainable Productivity of Agricultural System Using Subsurface Drip Irrigation, J. Agric. Sci. Technol. 881-888 (2011)

2. J.E. Ayars, R.A. Schoneman, F. Dale, B. Meso, P. Shouse, Managing Subsurface Drip Irrigation in the Presence of Shallow Ground Water, Agric. Water Manage. 47, 243264 (2001)

3. C.R. Camp, Subsurface Drip Irrigation: A Review. Trans. ASAE 41, 1353-1367 (1998)

4. C.R. Camp, P.J. Bauer, P.G. Hunt, Subsurface Drip Irrigation Lateral Spacing and Management for Cotton in the Southeastern Coastal Plain. Trans. ASAE 40, 993-999 (1997)

5. J.E. Ayars, C.J. Phene, R.B. Hutmacher, K.R. Davis, R.A. Schoneman, S.S. Vail, R.M. Mead, Subsurface Drip Irrigation of Row Crops: A Review of 15 Years of Research at the Water Management Research Laboratory, Agric. Water Manage 42, 1(-27 (1999)
6. K.C. Stone, P.J. Bauer, W.J. Busscher, J.A. Millen, Narrow Row Corn Production with Subsurface Drip Irrigation, Appl. Eng. Agric. 24, 455-464 (2008)

7. R.B. Hutmacher, K.R. Davis, S.S. Vail, M.S. Peters, A. Nevares, J. Covarrubias, Root Distribution of Cotton: Effects of Water Application Amounts under Subsurface Drip Irrigation, In 1998 Beltwide Cotton Conference, San Diego, CA. 05-09 Jan. 1998. Natl. Cotton Counc. Am. Memphis, TN (1998)

8. R.M.A. Machado, M.D.G. Oliveira, Tomato Root Distribution, Yield and Fruit Quality under Different Subsurface Drip Irrigation Regimes and Depths, Irrig. Sci. 24, 15-24 (2005)

9. C.J. Phene, K.R. Davis, R.B. Hutmacher, B. Baryosef, D.W. Meek, J. Misaki, Effect of High-Frequency Surface and Subsurface Drip Irrigation on Root Distribution of Sweet Corn, Irrig. Sci. 12, 135-140 (1991)

10. L.J. Schwankl, S.R. Grattan, E.M. Miyao, Drip irrigation burial depth and seed planting depth effects on tomato germination, in Proceedings of the Third International Irrigation Symp. Oct. 28- Nov.1 Phoenix, Arizona. ASAE, St. Joseph, Michigan (1990), pp. 682-687

11. I.G. Rubeiz, N.F. Oebker, J.L. Stroehlein, Subsurface drip irrigation and urea phosphate fertigation for vegetables on calcareous soils, J. Plant Nutrition 12, 1457-1465 (1989)

12. G. Rallo, C. Agnese, M. Minacapilli, G. Provenzano, Comparison of SWAP and FAO Agro-Hydrological Models to Schedule Irrigation of Wine Grapes, J. Irrig. Drain. Eng. 138, 581-702 (2012)

13. J. Šimůnek, M.T. van Genuchten, M. Sejna, The HYDRUS software package for simulating two-and three-dimensional movement of water, heat and multiple solutes in variably saturated media. Technical Manual. Version 1.0. PC Progress, Prague, Czech Republic (2006), p. 241

14. G. Provenzano, Using HYDRUS-2D simulation model to evaluated soil volume in subsurface drip irrigation systems, J. Irrig. Drain. Eng. ASCE 133, 342-349 (2007)

15. J. Šimůnek, M.Th. van Genuchten, M. Šejna, The HYDRUS Software Package for Simulating Twoand ThreeDimensional Movement of Water, Heat, and Multiple Solutes in Variably-Saturated Media. Technical Manual, Version 2.0, PC Progress, Prague, Czech Republic (2011), p. 258

16. R.A. Feddes, P.J. Kowalik, H. Zaradny, Simulation of field water use and crop yield. Pudoc, Centre Agric. Publ. Doc., Wageningen, 1978

17. J.A. Vrugt, M.T. Van Wijk, J.W. Hopmans, J. Šimůnek, One-, two-, and three dimenional root uptake functions for transient modeling, Water Resour. Res. 37, 2457-2470 (2001)

18. R.G. Allen, L.S. Pereira, D. Raes, M. Smith, Crop Evapotranspiration: Guidelines for computing crop water requirements. FAO Irrigation and Drainage Paper 56, Food and Agriculture Organization of the United Nations, Rome (1998), p. 333

19. G. Rallo, G. Provenzano, Discussion of "Laboratory and field calibration of the Diviner 2000 probe in two types of soil" by J. Haberland, PhD, R. Galvez, C. Kremer, PhD, C. Carter, J. Irrig. Drain. Eng. 140, 4 (2014). 141, doi:10.1061 (/ASCE) IR. 1943-4774.0000856 (2015)

20. B. Douh, A. Boujelben, S. Khila, A. Bel Haj Mguidiche, Effect of subsurface drip irrigation system depth on soil water content distribution at different depths and times after irrigation, Larhyss J. 13, 7-16 (2013) 